\title{
Routine Vaccination for Travelers from Emerging Countries: Epidemiological Profile of a Public Travel Medicine Clinic in Sao Paulo/Brazil
}

\author{
Dennis Minoru Fujita ${ }^{1,2^{*}}$, Karina Takesaki Miyaji ${ }^{3}$, Marta Heloisa Lopes ${ }^{3}$, Heitor Franco de Andrade Júnior², \\ Expedito José de Albuquerque Luna ${ }^{2}$
}

${ }^{1}$ Instituto Federal de Educação, Ciência e Tecnologia de São Paulo, São Paulo, Brazil

${ }^{2}$ Instituto de Medicina Tropical de São Paulo - USP, São Paulo, Brazil

${ }^{3}$ Ambulatório dos Viajantes e CRIE - Centro de referência para Imunobiológicos Especiais - FMUSP-HC System, São Paulo, Brazil

Corresponding Author: Dennis Minoru Fujita, PhD, Professor, Av. Dr. Enéas Carvalho de Aguiar, $470-1^{\circ}$ andar, CEP: 05403-000, São Paulo, Brazil. Tel: +55-1130618649, Email: dmfujita@usp.br

Received October 9, 2018; Accepted February 10, 2019; Online Published March 1, 2019

\begin{abstract}
Introduction: Emerging countries have increased their presence in international travel (46.8\% of travels). Pre- and post-travel consultations may provide insights about travelers' health.

Methods: A retrospective descriptive analysis of the medical data of all travelers assisted at Ambulatório dos Viajantes, a free public health clinic for travelers in São Paulo, Brazil, from January to December 2016 was performed. The patients were profiled based on post-travel consultation data and screened by gender, age according to the United Nations working-age population distribution (0-14 years, children; 15-24 years, youths; 25-65 years, working age; over 65 years, older persons), travel destination, and diseases that affected travelers.

Results: In 2016 ( $\mathrm{n}=280$ appointments), 93.92\% of clients received some type of vaccine (regular or booster dose). Post-travel consultations $(\mathrm{n}=27 ; 9.64 \%)$ were predominantly male $(62.96 \%$ of appointments) and comprised cases of malaria $(44.4 \% ; 6$ positive cases of Plasmodium falciparum, 4 positive cases of Plasmodium vivax, and 2 unclassified), fever (7.4\%), AGE - acute gastroenteritis (7.4\%), hepatitis A (3.7\%), nausea $(3.7 \%)$, insect bite $(3.7 \%)$, abdominal pain $(3.7 \%)$, arthralgia $(3.7 \%)$, vaginal discharge $(3.7 \%)$, and cases under investigation (18.5\%). Brazilian travelers presented the same incidence of post-travel counseling as developed countries' travel medicine clinics ( 9\%). Conclusion: Immunization in pre-travel counseling may reduce the importation of preventable infectious diseases and increase Brazilians' traveler vaccine coverage, a current concern in the country.

Keywords: Clinics, Counseling, Vaccination
\end{abstract}

Citation: Fujita DM, Miyaji KT, Lopes MH, de Andrade Júnior HF, de Albuquerque Luna EJ. Routine vaccination for travelers from emerging countries: epidemiological profile of a public travel medicine clinic in Sao Paulo/Brazil. Int J Travel Med Glob Health. 2019;7(1):13-17. doi:10.15171/ ijtmgh.2019.04.

\section{Introduction}

Travelers from emerging countries, such as the BRICS countries (Brazil, Russia, India, China, and South Africa), have increased their numbers in the international travel market, reaching $46.8 \%$ in $2016 .{ }^{1}$ Protective measures were established by agencies in some developed countries to avoid the importation of travel-related infectious diseases by incoming BRICs travelers based on previous experience with unhealthy travelers, especially immigrants.

Developed countries have improved their cross-border policies, created websites with health orientations and protective measures for travelers, expanded travel medicine clinics network, and have taken other actions to protect their travelers. $^{2}$
Some emerging countries have established similar policies in recent years, because their travelers began visiting endemic regions around the world, thus demanding preventive travel healthcare.

In Brazil, travel medicine healthcare began in the $1990{ }^{\prime} \mathrm{s}^{3}$ with the first Travel Medicine Clinic established in Rio de Janeiro (1997). After three years, the efforts made in that clinic resulted in the creation of the Instituto Emilio Ribas in São Paulo. In 2001, the University of São Paulo-Medical School Health System (FMUSP-HC system) established the Ambulatório dos Viajantes. These clinics are public and provide free healthcare.

Travel medicine in Brazil was limited to preventing domestic disease transmissions, with the protocol of immunization

Copyright $(0) 2019$ The Author(s). This is an open-access article distributed under the terms of the Creative Commons Attribution License (http:// creativecommons.org/licenses/by/4.0), which permits unrestricted use, distribution, and reproduction in any medium, provided the original work is properly cited. 
check-ups of travelers for preventable diseases, such as yellow fever. The international outbound flow was not representative and aimed toward developed countries considered safe.

Pre- and post-travel consultation is a service that has increased in the last 5 years because of the emergence of new international travel destinations, mainly in poor nations. In 2017, travel medicine clinics became available in all state capitals of Brazil (Table 1), with a high concentration of them in São Paulo state ( $\mathrm{n}=87$ clinics).

The aims of this retrospective study were to assess the epidemiological profiles of travelers who consulted at a Public Travel Medicine Clinic in São Paulo and to evaluate pre-travel counseling as a preventive measure for avoiding travel-related diseases.

\section{Methods}

A retrospective descriptive analysis was made of the medical data of travelers assisted in Ambulatório dos Viajantes from January to December, 2016. The Ambulatório dos Viajantes - FMUSP-HC System, located in São Paulo, Brazil, provides free public healthcare to around 20 travelers per month. The patients were profiled based on post-travel consultations, screening by gender, age according to the United Nations working age population distribution ${ }^{4}$ (0-14 years, children; 15-24, youths; 25-65 years, working age; over 65 years, older persons), travel destination, and diseases that affected travelers.

\section{Results}

The number of travel medicine clinics in Brazil was 132 in 2014 and increased to 237 in 2016 (79.5\%) with greater participation from the private sector (from 33 to 112 units) and a quantitative development in São Paulo (87 units [128.5\%], 2016).

In 10 years, Brazil presented a constant development in the framework of travel with 96.2 million travelers on domestic flights. The second half of 2015 showed a $7.4 \%$ decrease in domestic travel compared to the previous period in $2014 .^{5}$

The appointments in Ambulatório dos Viajantes accompanied this decline ( $\mathrm{n}=461$ in 2012; $\mathrm{n}=280$ in 2016), because of the economic instability that reduced the amount of travel (domestic and international).

From 2012 to 2014, the number of consultations peaked in January with similar figures in the following months, except in May when the clinic became an exclusive immunization center for influenza.

The number of appointments in 2015 and 2016 peaked in the second half of the year, with 2 months of high increase (July and December in 2015; October and November in 2016).

The mean values of pre-travel and post-travel counseling

Table 1. Travel Medicine Clinics - Brazil (2014/2017)

\begin{tabular}{|c|c|c|c|c|c|c|c|c|c|c|}
\hline \multirow{2}{*}{ State } & \multicolumn{4}{|c|}{ Administration } & \multirow[t]{2}{*}{2014} & \multicolumn{4}{|c|}{ Administration } & \multirow{2}{*}{2017} \\
\hline & Federal & State & Municipal & Private & & Federal & State & Municipal & Private & \\
\hline Acre & 4 & - & - & - & 4 & 4 & - & - & - & 4 \\
\hline Alagoas & 2 & - & - & - & 2 & 2 & - & - & - & 2 \\
\hline Amazonas & 1 & - & 1 & - & 2 & 1 & - & 1 & - & 2 \\
\hline Amapá & 1 & - & - & - & 1 & 1 & - & - & - & 1 \\
\hline Bahia & 4 & - & 1 & 2 & 7 & 6 & - & 1 & 11 & 18 \\
\hline Ceará & 3 & - & - & - & 3 & 3 & - & - & - & 3 \\
\hline Distrito Federal & 1 & - & - & 2 & 3 & 1 & - & - & 9 & 10 \\
\hline Espírito Santo & 1 & - & - & - & 1 & 1 & - & - & - & 1 \\
\hline Goiás & 1 & - & - & - & 1 & 1 & - & - & 1 & 2 \\
\hline Maranhão & 2 & - & - & - & 2 & 1 & - & - & - & 1 \\
\hline Minas Gerais & 1 & - & 1 & 2 & 4 & 1 & - & 2 & 9 & 12 \\
\hline Mato Grosso do Sul & 3 & - & - & - & 3 & 3 & - & - & 3 & 6 \\
\hline Mato Grosso & 2 & - & - & - & 2 & 2 & - & - & - & 2 \\
\hline Pará & 1 & - & - & 1 & 2 & 1 & - & - & 2 & 3 \\
\hline Paraíba & 1 & - & 1 & - & 2 & 2 & - & 2 & 1 & 5 \\
\hline Pernambuco & 1 & - & 3 & - & 4 & 1 & - & 3 & 1 & 5 \\
\hline Piauí & 2 & - & - & - & 2 & 2 & - & - & 1 & 3 \\
\hline Paraná & 5 & - & 1 & 5 & 11 & 5 & - & 1 & 6 & 12 \\
\hline Rio de Janeiro & 1 & - & 5 & - & 7 & 2 & - & 6 & 6 & 14 \\
\hline Rio Grande do Norte & 1 & - & - & - & 1 & 3 & - & - & - & 3 \\
\hline Rondônia & 3 & - & - & - & 3 & 1 & - & 2 & 1 & 4 \\
\hline Roraima & 3 & - & - & - & 3 & 3 & - & - & - & 3 \\
\hline Rio Grande do Sul & 3 & - & 1 & 1 & 5 & 3 & - & 2 & 2 & 7 \\
\hline Santa Catarina & 4 & - & 7 & 6 & 17 & 3 & - & - & 14 & 25 \\
\hline Sergipe & 1 & - & - & - & 1 & 1 & - & - & - & 1 \\
\hline Total & 55 & 2 & 41 & 33 & 132 & 57 & 3 & 57 & 112 & 237 \\
\hline
\end{tabular}


Table 2. Patients Attended in Pre- and Post-consultation - 2012/2016

\begin{tabular}{llllll}
\hline Year & Pre & \% & Post & \% & Total \\
\hline 2012 & 411 & 89.15 & 50 & 10.85 & 461 \\
2013 & 415 & 90.61 & 43 & 9.39 & 458 \\
2014 & 403 & 88.77 & 51 & 11.23 & 454 \\
2015 & 294 & 94.84 & 16 & 5.16 & 304 \\
2016 & 253 & 90.36 & 27 & 9.64 & 280 \\
Mean value & & 90.75 & & 9.25 & \\
\hline
\end{tabular}

were $90.75 \%$ and $9.25 \%$, respectively, from 2012 to 2016 (Table 2).

\section{Description of Appointments, 2016}

In 2016 (Table 3), there were 280 appointments with 93.92\% of clients receiving some type of vaccine (regular or booster dose); $36.4 \%$ were immunized for yellow fever. It is an important protocol for immunization update in pretravel counseling to minimize the negative effects of the low vaccination coverage (based on routine immunizations established by World Health Organization) recorded in recent years (Table 4).

Travel destinations were distributed by continent as follows: Asia, 33.1\%; Africa, 28.8\%; Central and South America, $24.8 \%$; Europe (Germany, 1.8\%; 2 or more countries in the European Union, 5.8\%; Eastern Europe, 0.9\%); New Zealand and Australia, 3.0\%; and North America/Canada, 1.5\%.

The age group ranged from 4 to 76 years with a female predominance $(60.7 \%$ in counseling) presenting the following distribution: 0-14 (2.5\%), 15-24 (14.28\%), 25-65 (76.79\%), and over 65 (6.43\%).

Post-travel consultations ( $\mathrm{n}=27,9.64 \%)$ were predominantly male $(62.96 \%$ of appointments) and included cases of malaria (44.4\% - 6 positive cases of Plasmodium falciparum, 4 positive cases of Plasmodium vivax, and 2 unclassified), fever (7.4\%), AGE - acute gastroenteritis (7.4\%), hepatitis A (3.7\%), nausea $(3.7 \%)$, insect bite $(3.7 \%)$, abdominal pain $(3.7 \%)$, arthralgia (3.7\%), vaginal discharge (3.7\%), and cases under
Table 4. Vaccine Coverage (\%) - Brazil - 2012/2016

\begin{tabular}{lllllll}
\hline & $\mathbf{2 0 1 2}$ & $\mathbf{2 0 1 3}$ & $\mathbf{2 0 1 4}$ & $\mathbf{2 0 1 5}$ & $\mathbf{2 0 1 6}$ & $\mathbf{2 0 1 7}$ \\
\hline BCG & 105.69 & 107.42 & 107.28 & 105.08 & 95.55 & 93.41 \\
Rotavirus & 86.37 & 93.52 & 93.44 & 95.35 & 88.98 & 76.52 \\
Meningococcal & 96.18 & 99.70 & 96.36 & 98.19 & 91.68 & 78.72 \\
Pentavalent & 93.80 & 95.89 & 94.85 & 96.30 & 89.27 & 76.48 \\
Pneumococcal & 88.39 & 93.57 & 93.45 & 94.23 & 95 & 83.56 \\
Poliomyelitis & 96.55 & 100.71 & 96.76 & 98.29 & 84.43 & 78.47 \\
Hepatitis A & - & - & 60.13 & 97.07 & 71.58 & 77.04 \\
MMR & 99.50 & 107.46 & 112.8 & 96.07 & 95.41 & 85.21 \\
Tetravalent & - & 34.19 & 90.19 & 77.37 & 79.04 & 71.65 \\
\hline
\end{tabular}

investigation (18.5\%) with a male predominance.

\section{Discussion}

The recent participation of emerging countries (such as the BRICS countries) in international travel requires the improvement of preventive measures to protect their citizens and reduce the potential risk for the importation of infectious diseases.

In Brazil, travel medicine has improved in the last 5 years, ${ }^{6}$ and specialized clinics have become an important tool in this prevention system. ${ }^{7}$

In 2017, there were 237 travel medicine clinics located in all state capitals of Brazil (27 states), with a high concentration in São Paulo state $\left(\mathrm{n}=38\right.$ in 2014 to $\mathrm{n}=87$ in 2017). ${ }^{8}$

Significant investment in travel medicine by the private sector indicates that it is a promising and relevant segment of the travel industry (221.43\% from 2014 to 2016).

The increase in number of facilities and the decrease in travel in Brazil led to a significant reduction in the number of consultations at the Ambulatório dos Viajantes, FMUSP-HC System (33.04\% in 2014-2015 to $7.89 \%$ in 2015-2016) after the second half of 2015 (Figure 1).

The main peak in number of consultations occurred in January due to the summer school holidays in Brazil that start at the end of December, ${ }^{9}$ but family vacations to international destinations increase significantly from the second week of the

Table 3. Ambulatório dos Viajantes - HC - Appointments by Month, Age, Gender and Destination - 2016

\begin{tabular}{|c|c|c|c|c|c|c|c|c|c|}
\hline Month & \multicolumn{2}{|l|}{ (n) } & Month & (n) & Month & (n) & Month & (n) & Total (n) \\
\hline January & \multicolumn{2}{|l|}{19} & April & 6 & July & 24 & October & 24 & \\
\hline February & \multicolumn{2}{|l|}{14} & May & 7 & August & 31 & November & 42 & 280 \\
\hline \multicolumn{10}{|c|}{ Appointments - Total 2016} \\
\hline \multicolumn{3}{|c|}{ Pre-Travel Counselling } & 253 & & Post Travel C & lling & & 27 & \\
\hline \multicolumn{10}{|c|}{ Appointments by Age, Gender and Destination - 2016} \\
\hline Age & $(\mathbf{n})$ & $\%$ & \multicolumn{3}{|c|}{ Destination } & & Total (n) & \multicolumn{2}{|l|}{$\%$} \\
\hline $0-14$ & 7 & 2.5 & \multicolumn{3}{|l|}{ África } & & 94 & \multicolumn{2}{|l|}{28.83} \\
\hline $15-24$ & 40 & 14.28 & \multicolumn{3}{|l|}{ Asia } & & 108 & \multicolumn{2}{|l|}{33.13} \\
\hline $25-65$ & 215 & 76.79 & \multicolumn{3}{|c|}{ Central And South America } & & 81 & \multicolumn{2}{|l|}{24.85} \\
\hline \multirow[t]{2}{*}{ over 65} & \multirow[t]{2}{*}{18} & 6.43 & \multicolumn{3}{|c|}{ Germany } & & 6 & \multicolumn{2}{|l|}{1.84} \\
\hline & & & \multicolumn{3}{|c|}{$\mathrm{NZ}$ and Australia } & & 10 & \multicolumn{2}{|l|}{3.07} \\
\hline Female & 170 & 60.71 & \multicolumn{3}{|c|}{ Eastern European } & & 3 & \multicolumn{2}{|l|}{0.92} \\
\hline Male & 110 & 39.29 & \multicolumn{3}{|l|}{ Europe } & & 19 & \multicolumn{2}{|l|}{5.83} \\
\hline
\end{tabular}




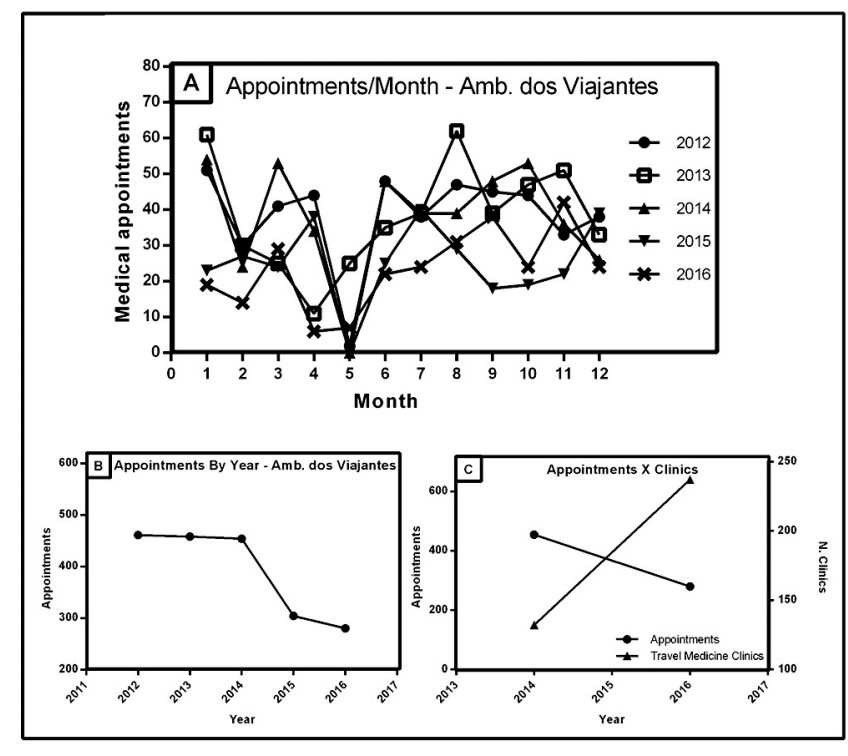

Figure 1. Appointments From 2012 to 2016.

month when the number of pre-travel appointments grows. The second period is related to the winter school vacations, an expected situation due to the increase in travels. Through the appointments' flow, it can be assumed that Brazilian travelers seek assistance in the imminence of a trip, a matter of concern.

Allied to travel medicine facilities, the Brazilian government established more preventive measures such as a handbook for travelers published in 2012 by the Brazilian National Health Surveillance Agency, a government agency responsible for hygiene inspections in Brazilian territory. ${ }^{10}$ It is a small guide for travelers with general information about how to check an individual's health condition, expected infectious diseases in some tourist destinations, routes of transmission of infectious diseases, as well as protective measures and behavior to take during a trip.

Additionally, the Ministry of Health created a website with specific information for Brazilian travelers to international destinations in 2014, ${ }^{11}$ which improved this protective network by being updated regularly.

This web page includes links to the main health information websites for international travelers, treaties and agreements with some countries that provide free medical care for Brazilian citizens, locations of public travel health clinics and immunization centers in Brazil, and other important information for safe travel in Brazil and abroad.

Despite this apparent reduction in tourism activity in Brazil, the current network of travel medicine clinics should be maintained due to its importance as a source of strategic health planning for the prevention of infectious diseases.

The epidemiological profile of Ambulatório dos Viajantes presents this preventive orientation with a mean value of $90.75 \%$ in pre-travel counseling.

The protocol for travelers' vaccine check-up contributes to cross-border protection, reducing the potential for infectious disease importation and domestic spread through the immunization of travelers for the main preventable infectious diseases. This is an important strategy considering the current low MMRV (70.69\% in 2017) and polio (77\% in 2017) vaccine coverage in Brazil.

Age, destination, and gender are important data for estimating the potential risks of travelers' exposure. Some studies have stated that young travelers are more susceptible to risks than senior travelers. ${ }^{12}$

The data in the current study indicate a significant flow of youth and adult travelers to Asia (33.13\%), mainly to the southeastern area (Thailand), with a real potential for the importation of infectious diseases. ${ }^{13}$

The international destinations most visited by Brazilians, however, are South American countries, which have a similar potential for outbreaks of neglected diseases. North America and Europe, considered "safe places" by some Brazilian travelers, present a potential risk as sources of the reemergence of preventable infectious diseases, like measles, in Brazil. ${ }^{14}$

According to the current data, Brazilian travelers refer to Ambulatório dos Viajantes only for international travels, disregarding that some regions of the country are highly endemic, as observed in recent outbreaks of malaria, ${ }^{15}$ yellow fever, ${ }^{16}$ and measles. ${ }^{17}$

Males present more risky behavior than women ${ }^{18}$ as evidenced by the low male demand (39.29\%) and the predominance in post-travel consultation (62.96\%).

The Ambulatório dos Viajantes - FMUSP-HC System shares its space with a referral laboratory for the diagnosis of malaria of the Superintendência de Controle de Endemias da Secretaria de Estado da Saúde de São Paulo - SUCEN (Superintendence of Control of Endemic Diseases of the State Department of Health of São Paulo) that is devoted to post-travel consultation, resulting in a great number of positive cases (44.4\%) in this biased population. Adults (25-65 years, 40.7\%) and the older persons group (over $65,33.3 \%$ ) predominate in post-travel consultation, confirming the prevalence reported in other studies. ${ }^{12,19}$

The same facility includes the Referral Center for Special Immunizations (CRIE - FMUSP-HC System) with free delivery and administration of vaccines for preventable infectious diseases, especially for travelers. This department issues the International Certificate of Vaccination or Prophylaxis. Due to this social function for immunization, the clinic shows a relative reduction in the number of appointments (Figure 1A) for the period of the national campaign for influenza flu vaccination, which occurs in May (only 7 consultations were allowed in May 2016). Other travel medicine clinics in Brazil offer assistance for routine vaccinations such as for BCG, hepatitis $\mathrm{A}$ and $\mathrm{B}$, rotavirus, meningococcal $\mathrm{C}$, pentavalent (diphtheria, tetanus, pertussis, hemophilus influenzae, type $\mathrm{b}$ meningitis, and poliomyelitis), pneumococcal, poliomyelitis, yellow fever, MMR vaccine, tetravalent (MMR+varicella), DTP (diphtheria, tetanus, and pertussis), adult DPLA (diphtheria and tetanus), influenza, and quadrivalent HPV. ${ }^{3}$

Allied to this strategy of vaccine coverage surveillance, in pre-travel counseling, physicians assist patients (based on their travel itinerary) regarding the main infectious diseases in the area to be visited. Most importantly, they advise patients on the specific preventive measures to adopt.

These protocols reduced post-travel consultations in 2016 


\section{Research Highlights}

\section{What Is Already Known?}

Preventive vaccination in pre-travel counseling has become an important strategy for the protection of travelers from emerging countries due to their increased participation in international travels.

\section{What This Study Adds?}

What this study adds? Brazilian travelers presented an incidence of post-travel counseling similar to that observed in travel clinics of developed countries ( 9\%).

(9.645\%) and indicate that travelers are more concerned. Current rates of pre- and post-travel assistance are similar to those of travel medicine clinics in developed countries. ${ }^{19-22}$

\section{Conclusion}

The increase in Brazilian participation in international travel was followed by the establishment of protective measures. The implementation of a counseling website for travelers and the expansion of travel medicine clinics indicate the potential for changing the be havior of Brazilian travelers, based on the high percentage of pre-travel counseling conducted by the Ambulatório dos Viajantes - FMUSP-HC System.

According to the current data, women seek pre-travel medicine assistance more than men, and Southeast Asia is the main travel destination for patients who seek pre-travel consultation, especially the youth and adults traveling to Thailand. Post-travel consultation has a male predominance, and the low number indicates that pre-travel counseling is an important activity for protecting travelers.

The immunization protocol adopted in the Ambulatório dos Viajantes becomes important because of the current low vaccine coverage rate in Brazil.

\section{Authors' Contributions}

All authors contributed equally to this study.

\section{Conflict of Interest Disclosures}

The authors state they have no conflicts of interest to declare.

\section{Ethical Approval}

The study was approved by the Research Ethics CommitteeFMUSP-HC System, Process: CAAE 22239713.0.0000.0065, Technical Report No 743.367, issued on July 23, 2014.

\section{Funding/Support}

None.

\section{Acknowledgments}

The authors wish to acknowledge the assistance of the Ambulatório dos Viajantes e CRIE - Centro de Referência para Imunobiológicos Especiais - FMUSP-HC System, Federal Institute of Education, Science and Technology of São Paulo, Instituto de Medicina Tropical de São Paulo and CAPES.

\section{References}

1. United Nations World Tourism Organization (UNWTO). Tourism Highlights - 2016. Geneva: UNWTO; 2016.

2. Fujita DM, Nali LH, Urbano PR, Soeiro DM, Andrade HF Jr. The fast transmission of infectious diseases around the world - a new concern to the public health. Braz J Infect Dis. 2016;20(5):513515. doi:10.1016/j.bjid.2016.06.003.

3. Igreja RP. [Travel Medicine: a new field of work for the specialist in Infectious and Parasitic Diseases]. Rev Soc Bras Med Trop. 2003;36(4):539-540. doi:10.1590/S0037-86822003000400020.

4. Mun N, Lai S. Global Population Age Structures and Sustainable Development. New York: United Nations Population Division; 2016.

5. Brazil. Dados do Anuário do Transporte Aéreo. Brasília; 2016.

6. Chaves Tdo S, Alves JR, Lopes MH. Pre-travel counselling in Brazil. Travel Med Infect Dis. 2015;13(4):340-341. doi:10.1016/j. tmaid.2015.03.007.

7. Horvath LL, Murray CK, Dooley DP. Effect of maximizing a travel medicine clinic's prevention strategies. J Travel Med. 2005;12(6):332-337. doi:10.2310/7060.2005.12606.

8. Brazil. Travel Medicine Clinics - Anvisa. Available at: http://portal. anvisa.gov.br/centros-de-orientacao-do-viajante. Accessed March 16, 2017.

9. dos Santos RP, Konkewicz LR, Nagel FM, et al. Changes in hand hygiene compliance after a multimodal intervention and seasonality variation. Am J Infect Control. 2013;41(11):10121016. doi:10.1016/j.ajic.2013.05.020.

10. Brazil. Saúde do Viajante. Brasília: ANVISA; 2012.

11. Brazil. Viajante BR. Brazilian Ministry of Health. Available at: http://portalsaude.saude.gov.br/index.php/o-ministerio/principal/ secretarias/svs/viajante. Accessed May 2, 2017.

12. Vilkman K, Pakkanen SH, Laaveri T, Siikamaki H, Kantele A. Travelers' health problems and behavior: prospective study with post-travel follow-up. BMC Infect Dis. 2016;16:328. doi:10.1186/ s12879-016-1682-0.

13. Dash AP, Bhatia R, Sunyoto T, Mourya DT. Emerging and reemerging arboviral diseases in Southeast Asia. J Vector Borne Dis. 2013;50(2):77-84.

14. Nali LH, Fujita DM, Salvador FS, et al. Potential measles transmission risk in mass gatherings: Are we safe for the Olympic games--Rio 2016? J Travel Med. 2016;23(4). doi:10.1093/jtm/ taw026.

15. Garcia M. Situação epidemiológica das arboviroses e malária Brasil, 2018. Brasília; 2018.

16. Fujita DM, da Silva Nali LH, Salvador FS, de Andrade Junior HF. Recommendations for travellers during the yellow fever outbreaks in Brazil-2018. J Travel Med. 2018;25(1). doi:10.1093/jtm/tay016.

17. Brazil. Situação dos Casos de Sarampo nos Estados de Roraima e Amazonas-2018 Monitoramento da situação epidemiológica de sarampo nos estados de Roraima e Amazonas. Brasilia; 2018.

18. Aggleton P, Bell SA, Kelly-Hanku A. 'Mobile men with money': HIV prevention and the erasure of difference. Glob Public Health. 2014;9(3):257-270. doi:10.1080/17441692.2014.889736.

19. Buhler S, Ruegg R, Steffen R, Hatz C, Jaeger VK. A profile of travelers--an analysis from a large swiss travel clinic. J Travel Med. 2014;21(5):324-331. doi:10.1111/jtm.12139.

20. Marchand C, Merrina F, Gagnayre R, Bouchaud O. A descriptive study of advising practices during travel health consultations in France. J Travel Med. 2017;24(5). doi:10.1093/jtm/tax042.

21. Rowe K, Chaves N, Leder K. Challenges to providing pre-travel care for travellers visiting friends and relatives: an audit of a specialist travel medicine clinic. J Travel Med. 2017;24(5). doi:10.1093/jtm/ tax038.

22. Rodrigo Saez L, Riestra Menendez S, Fernandez Rodriguez E, Fernandez Velazquez MR, Garcia Alonso S, Lauret Brana ME. Epidemiological study of the prevalence of Helicobacter pylori infection in the general population in Asturias, Spain. Rev Esp Enferm Dig. 1997;89(7):511-522. 